\title{
La mirada a través de la cámara / Cine, escenas puberales y teorías sexuales juveniles
}

\author{
Christian Bonnet*, Julie Chevalier, Clarisse Vollon y Guy Gimenez
}

\author{
Aix Marseille Université (AMU)
}

Recepción: 15 de diciembre de 2019; aceptación: 2 de febrero de 2020

\begin{abstract}
Resumen
El artículo expone una secuencia clínica analítica con una adolescente que, durante una sesión, hace una asociación con una escena de una película. El texto articula los conceptos de mirada a cámara (Vernet) y de mirada a través de la cámara (Bonnet), como nociones que dan cuenta particularmente de la construcción de escenas, e incluso de fantasmas adolescentes. La concepción de las escenas puberales (Gutton) y de los escudos [blasons] del cuerpo adolescente será puesta en tensión con la lógica de la mirada a través de la cámara para abordar mejor la lógica de las teorías sexuales juveniles. La originalidad de estas tres teorías sexuales juveniles radica en la estructura formal que permite percibirlas en el discurso de los adolescentes. Así, en la unión entre la mirada a través de la cámara y las teorías sexuales juveniles, aparecen en la trasferencia las condiciones de una construcción del género en la adolescencia.
\end{abstract}

Palabras clave: Psicoanálisis | Mirada a cámara | Mirada a través de la cámara | Teorías sexuales juveniles | Escenas puberales | Escudo

The gaze by the camera / Cinema, puberty scenes and juvenile sexual theories

Abstract

The article unveils an analytical clinical sequence with Olga, a teenager associating in a session around a scene from the film Freaks by T. Browning. The text articulates the concepts of look at the camera (Vernet) and gaze by the camera (Bonnet) as giving particular account in the course of the treatment of the construction of scenes, even adolescent fantasies. Olga describes in turn the gaze of a character from the film, at the same time as she deploys her gaze in the space of the session and offering herself to the analyst's gaze with the sign of a wound on her body. This wound constitutes her like a beroine with a scar, that is to say, a carrier of a sign, a mark, even a Blazon of the female body. The conception of pubertal scenes (Gutton) and Blazons of the adolescent body (Bonnet), will be put in tension with the logic of the gaze by the camera in order to better approach the logic of juvenile sexual theories. We argue that beyond Freud's three infantile sexual theories, it becomes necessary in adolescent clinical analytics to forge extensions, redesigns and creations of original sexual theories. At the confluence of the infantile and the juvenile, we are trying to formalize the place of the genital in the field of puberty. Our proposal organizes three juvenile sexual theories: first the theory of the genital Blazons, then a theory of the embrace of the hero with the scar; finally a theory of the hero's test against the horde. The originality of these three juvenile sexual theories is due to the formal structure that gives them to be heard in the discourse of adolescents. So in the knotting between gaze by the camera and juvenile sexual theories appear in the transference the conditions of a construction of the genre in adolescence.

Keywords: Gaze by the camera| Pubertal scenes | Blazons | Juvenile sexual theories

En el marco de este coloquio, vuelvo con un deseo: el de retomar, prolongar y, en cierto modo, cumplir una parte de mis objetivos y del proyecto de mi texto anterior (Bonnet, 2018), en el que abordaba la articulación entre mirada a cámara, retórica de la imagen, escenas puberales y teorías sexuales. En esta ocasión, voy a plantear de un modo más preciso de qué modo los desafíos retóricos permiten pensar la noción de "mirada a través de la cámara” en el marco de una clínica de los procesos adolescentes; eso me conducirá a plantear por primera vez la formalización de tres teorías sexuales juveniles, verdadero cruce, en la trasferencia, entre escenas puberales y catexis [investissement] de escenas cinematográficas.

Para eso, presento un fragmento clínico de la terapia de Olga, una adolescente, centrándome en su propia mirada de la película Freaks (1932) de Todd Browning. El análisis se apropia primero del concepto de mirada a

*xtian.bonnet@gmail.com 
cámara, tal y como aparece en Vernet (1983), así como también de mi propuesta sobre la mirada a través de la cámara. Luego, articularé las condiciones retóricas de constitución de las escenas puberales en relación con las teorías sexuales juveniles, para establecer, por último, mi singular teorización. Así, examino lo que es una teoría sexual juvenil y cómo definir sus funciones en la sesión bajo transferencia por medio del surgimiento de la mirada a través de la cámara.

\section{Capítulo 1: Las lágrimas de Olga}

Olga atraviesa sus 17 años con el peso de las lágrimas y bajo la carga de los sollozos. Hoy se instala triste y su mirada alterna entre los reflejos de la ventana a su derecha y mi rostro a su izquierda... Durante mucho tiempo, sus llantos ocuparon todas las sesiones de los últimos dos años.

Olga suspira, gira un poco más hacia la ventana, el tiempo se suspende y me oigo decir en un a media voz: "Sí...".

Olga: "Sí, sí... Estoy triste otra vez en este momento... Vi una película, una película que usted debe conocer... Es vieja... Es en blanco y negro... Y, sobre todo, tiene monstruos. A usted le gustan los monstruos, lo sé. La hermana de una amiga lo tiene como profesor y usted habla de ellos... Sí, hay monstruos, montones de monstruos, verdaderos monstruos, distintos de los que se suelen ver, no trucos de cine".

En el silencio que sigue, le hago una pregunta: “¿De qué película hablás, qué viste?”. Olga fija su mirada intensamente en la ventana y, empezando a articular claramente las sílabas, dice: "Sí, esa película tiene muchos monstruos. El domingo me lastimé dibujando, sabe que hago dibujos con pluma y tinta. Me... En realidad, hice... Quiero decir, me corté la palma de la mano con la pluma de metal...".

El silencio vuelve. Le pregunto: "Con la pluma de metal... ¿Qué pasó?”.

Olga se fija cada vez más en la ventana y ahora el sol se posa sobre sus mejillas y su frente; arruga ligeramente los ojos por la luz: "Sí, dibujaba, quería dibujar. Hice... Hice cualquier cosa queriendo proyectar tinta sobre la hoja, así, de un golpe seco. Pensaba en usted, en la última sesión habíamos hablado de los soles negros de la melancolía, ya sabe, ese poema del tipo que se colgó, Nerval creo, y usted me dijo algo sobre los soles negros y entonces quería hacer soles negros y... Crac, me clavé la pluma en la palma de la mano; eso es también culpa suya... Bueno, eso creo".

“¿Eh?”, murmuré de forma semi-interrogativa, recordando cómo Nerval habitaba nuestra sesión anterior...

Olga retoma, todavía hundida en la luz: "Bueno, y entonces estoy herida, me duele, sangro, agarro esa película y la pongo. Es una película de monstruos en blanco y negro... Hay una escena donde se ve a una persona de espaldas, no se sabe quién es, es raro, inquietante, extraño; y esta persona es un chico, un chico raro, sentís que es raro, y ese chico se da vuelta poco a poco, despacio, ¿sabe?, se da vuelta hacia la derecha y lo ves. Lo ves, es un monstruo, está todo deformado; es monstruoso y su mirada gira hacia vos, gira hacia vos y de golpe te mira fijo a los ojos... Fijo a los ojos... Lo miré fijo a los ojos...".

Olga llora, solloza, se acurruca: “¡Usted lo sabe, el monstruo soy yo!”.

Y Olga desvía los ojos de la ventana y lentamente, mientras el sol baña su rostro entre los dedos desplegados como abanico bajo sus ojos, posa su mirada en la mía y, girando la palma hacia mí, me expone su cicatriz y repite: “ $¡$ Usted lo sabe, $¡$ el monstruo soy yo!”.

No diré nada más desde el punto de vista clínico, ni de las asociaciones que se relacionan con los monstruos, ni de lo que pude proponer en ese momento, solo diré que fue el momento de una construcción en el análisis en el sentido más freudiano que pueda darle a mi práctica. Sin embargo, así fue como concluyó la sesión: Olga se mira las manos, luego me mira intensamente: “¿Sabe?, no le dije el título de la película. En inglés es Freaks, creo que quiere decir 'los monstruos'... Yo soy su monstruito y solo usted me escucha, pero para eso debo pagar el precio. Le pago con mi plata [fric], con mi freaks, $M r$. Bonnet, ¿lo oye? Le pago con mi freaks". ${ }^{1}$

La sesión concluye.

\section{Capítulo 2: La mirada a través de la cámara}

A continuación, articularé los conceptos de "mirada a cámara" (Vernet, 1983) y de "mirada a través de la cámara" (Bonnet, 2018) con el tema de las escenas puberales (Gutton, 1991; 1996) y la retórica de la imagen en la transferencia. 


\section{Mirada a cámara}

La fórmula de mirada a cámara, en el marco del análisis fílmico, es de Marc Vernet, y aparece en su texto de 1983. Es una figura de la imagen fílmica que, apoyándose sobre el cuadro y abriéndolo hacia nosotros (espectador), nos mira, nos mira a nosotros, a nosotros que la miramos a los ojos desde la sala. La mirada a cámara cuestiona los efectos de nuestra mirada: ¿quién mira a quién? ¿Qué función tiene la mirada de uno en la mirada del otro? Esto permitió a Vernet ricos desarrollos sobre el sujeto-espectador. Esta puesta en abismo [mise en abyme] de las miradas de la obra y sobre la obra se relaciona con lo que Foucault (1966) proponía, en el íncipit de Las palabras y las cosas, con respecto a la mirada de Velázquez sobre el espectador. En el análisis que plantea Foucault de Las meninas, cuando la mirada del pintor se posa sobre los espectadores de la tela, por un lado, vuelve a cuestionar lo que es la tradición de los retratos en la pintura y, por el otro, define más radicalmente las condiciones mismas de la representación.

En el cruce entre Vernet y Foucault (1960), también convoco a las figuras de Arasse (1982; 1992; 2000), de Yates (1975) y de Barthes (1966), para apropiarme del término "retórico". El despliegue de imágenes puede pensarse como el ordenamiento de un hilo diacrónico, es decir, que permite una real discursividad. La retórica es el nombre que terminamos por darle al modo de despliegue y articulación de figuras y de motivos, como significantes que ordenan un verdadero relato. La mirada a cámara es una secuencia discursiva que une a la figura que mira al espectador con el motivo de una mirada que encuentra, construye y abraza a otra. La mirada a cámara es un componente original en una retórica que incluye al espectador en la mirada no solo sobre la obra sino de la obra misma, en un juego de manos que, por más ilusorio que sea, no deja de ser notable. A través de la mirada de una figura inscrita en el campo de la representación, cuando esta se vuelve hacia nosotros, podemos vernos expuestos, entonces, en nuestra propia mirada. Se trata de una operación ficticia de ensamble que moviliza las formas de la puesta en abismo [mise en abyme] como una inversión de las miradas.

Nuestra posición en la mirada se revela por el artefacto de la mirada a cámara, con la forma de un surgimiento, de una inversión. No se trata de un espejo, sino de una ficción. De una ficción construida, de una ficción retórica en el sentido más clásico del término: una imagen que piensa y construye discurso. El valor de esta ficción, desde un punto de vista psicopatológico, se deduce de su potencial para hacer emerger procesos identificatorios y movimientos múltiples para el espectador que se ve convocado a enfrentarse a sus movimientos voyeristas y exhibicionistas.

En el momento clínico con Olga, este concepto tiene un valor doble. El más evidente es el de la descripción que hace Olga de la escena de Freaks, con esa inversión del monstruo que mira al espectador desde la escena que lo descubre. El monstruo nos mira a los ojos, y Olga ve que la mira desde la película. De este modo, la mirada a cámara produce en Olga un sobrecogimiento notable. El segundo valor del concepto es precisamente la película, calificada casi como una antigüedad, con una referencia a su proximidad con mi edad, o con mi generación, incluyendo así la escena en la transferencia. En la mirada a cámara, Olga es vista por el monstruo, desde un universo patinado con la antigüedad de un blanco y negro que me incluye en esa temporalidad.

\section{Mirada a través de la cámara}

Ahora propongo pasar de la mirada a cámara a la mirada a través de la cámara (Bonnet, 2018). La mirada a través de la cámara es una noción específica de la clínica adolescente (o más bien de los procesos adolescentes) que permite pensar de qué modo la mención, la evocación, la descripción de una escena ocupa lugar en la doble mirada del paciente y del analista en sesión. Es importante precisar que esta noción solo tiene sentido en el espacio de interlocución de la sesión. Clínicamente, la mirada a través de la cámara suele tomar forma en dos tiempos. En un primer tiempo, el paciente evoca una escena de mirada a cámara en la que una figura de la ficción lo mira como espectador. En un segundo tiempo, el paciente indica qué efectos o vivencias lo embargan en su mirada de espectador sobre la figura cinematográfica, y opera dirigiendo el discurso al analista. En la transferencia, el paciente convoca el doble movimiento de aquel que lo mira (mirada a cámara) y de qué modo mira al que lo mira, exponiéndose ante el analista: soy mirado por la película y miro la película exponiéndome ante el analista en su mirada. En la mirada a través de la cámara, una mirada desde la película revela las condiciones de la mirada sobre la película y abre a la recuperación de ese movimiento en terapia, en sesión, en situación analítica y bajo transferencia.

Las condiciones de revelación del sujeto adolescente en el trabajo analítico encuentran una respuesta intere- 
sante en la fórmula de mirada a través de la cámara. En efecto, por poco que el sujeto "esté" en ese "ojo" de la cámara, en ese momento convoca muy rápidamente las condiciones de un universo diegético. En ese universo, la película responde a otras películas así como también a recuerdos y a momentos de sesiones. Hay un mundo que el sujeto mira sin verlo y que, por momentos, surge y nos ve. Así, el sujeto se experimenta desde el lugar que ocupa en su propia mirada.

Una de las fórmulas posibles que uso se enuncia así: mientras que el espectador-sujeto suele ser captado por la mirada a cámara, en la mirada a través de la cámara, la mirada se vuelve el ojo del adolescente en el que él se exhibe en el lugar mismo de la mirada de la película. Así, puedo pensar que la mirada a través de la cámara es el ojo del adolescente por medio del cual se ofrece en exhibición a la mirada del analista, en la transferencia y solo en la transferencia. En la sesión, el proceso de transferencia puede ordenarse en el continuum identificatorio y voyerista: en un extremo, la mirada es la condición de una inmersión en la película, mientras que, en el otro extremo, la mirada se convierte en el intersticio, segmento, rendija y corte por el cual se ve y se roba la escena; el conjunto se ofrece a la mirada del analista.

Entonces, la mirada a través de la cámara es una fórmula que define la operación de despliegue de la interlocución en la sesión. El supuesto ojo, solicitado por las películas que evocan los adolescentes, es también el oído del analista, requerido y convocado por los cuestionamientos que surgen. ¿Quién escucha y quién mira a quién? En el espacio incierto del despliegue de las declaraciones del sujeto y a partir de las referencias a las películas mencionadas, siempre me intereso por aquello que insiste, de los procesos psíquicos adolescentes, en y por el surgimiento y señalamiento de esa mirada a través de la cámara, indisolublemente anudada a la transferencia. Eso permite remarcar, en un momento clínico en el que las cosas "con imágenes” ocupan masivamente la vida de los sujetos, todos los recursos retóricos de esos procesos y fenómenos.

Con Olga, analicemos ahora la manera en que la mirada a través de la cámara adquiere lugar y consistencia. Primero evoca los monstruos, que conozco, ya que, como dice ella, los menciono en mis clases. Después, irrumpen en su discurso los soles negros de la melancolía unidos a su herida y cicatriz reciente. Luego, se despliega la escena de la mirada a cámara del monstruo. Por último, está el punto clínico en el que insisto en el análisis: Olga desvía los ojos de la ventana y, lentamente, mientras el sol baña su rostro entre los dedos desplegados como abanico bajo sus ojos, posa su mirada en la mía y, girando la palma hacia mí, me expone su cicatriz y repite: “ $i$ Usted lo sabe, el monstruo soy yo!”. Esta secuencia es, precisamente, la cristalización de lo que denomino "mirada a través de la cámara".

En el momento en que Olga describe la escena de la mirada a cámara, pasa de una mirada hacia la ventana a una mirada sobre mí; mira entre sus dedos, recortando un encuadre particular para "su" y "mi" visión y, girando la palma de la mano, me expone la marca de su herida, su cicatriz, y suelta su sentencia: “ $i$ Usted lo sabe, el monstruo soy yo". Como además trabajé mucho sobre el héroe con cicatriz (Bonnet, 2014a, 2014b) y el tema de la exposición del cuerpo y de las marcas, en tanto estas serían escudos del cuerpo adolescente (Bonnet, 2007), puedo insistir en el valor de la marca en el cuerpo de Olga: un sol negro de la melancolía cuya culpa me concierne en la transferencia. Ella mira la luz y me mira alternativamente mientras describe una escena que vio en la película. En el momento en que describe la mirada del monstruo, me mira y me expone su marca. Aquí, la mirada a través de la cámara es un equivalente de una escena puberal, por cuanto presenta un escudo particular y hace surgir un nombramiento: "el monstruo soy yo". Olga se constituye en un héroe con cicatriz por el escudo que tiene en la palma de la mano. Esta escena puberal se ordena de modo transferencial por la operación de la mirada a través de la cámara que inscribe diegéticamente la escena de la mirada a cámara de Freaks.

En la transferencia, la sesión despliega una retórica de la imagen en el sentido de que la discursividad se ordena por medio de escenas que son, a la vez, evocadas (la mirada a cámara en Freaks que cuenta Olga) y puestas en relación con una escena construida (mirada que juega entre el recorte de los dedos y la luz, ofreciendo a la vista del analista la palma que tiene la cicatriz). ¿Qué presenta la película Freaks según la mirada de Olga? Una retórica que sustituye el mundo de Olga con escenas que sostienen sus deseos en la transferencia. Olga, vista por un monstruo, se ofrece a la mirada del analista como si fuera su monstruo en sesión.

\section{Capítulo 3: Olga y las teorías sexuales juveniles}

Doy ahora un paso teórico más allá del análisis del segmento clínico precedente y sostengo que no podría haber escenas puberales, mirada a través de la cámara y menos aún héroe con cicatriz que no se articularan con una propuesta de teorías sexuales juveniles. Expongo 
aquí el fruto de este trabajo ya presente en mis escritos anteriores sobre la construcción de las teorías sexuales juveniles.

¿Qué es una teoría sexual? Epistemológicamente, se trata, por supuesto, de lo que Freud (1905) plantea en los tres ensayos sobre teoría sexual. En mi lectura, se trata de una fórmula lógica que el sujeto pone a prueba en narraciones y relatos, considerando en una combinatoria las posibilidades, los límites y los efectos de esta teoría. En términos de Lévi-Strauss (1958), son enunciados cercanos a las fórmulas fundamentales de los mitos que, como instrumento lógico, permiten plantear paradojas y acomodarlas, por un tiempo al menos, exponiendo fórmulas, escenarios, hipótesis que ordenan la relación con el tiempo, la muerte, la sexualidad, la creación. Una teoría sexual permite multiplicar las preguntas, las tesis, detectar sus consecuencias e incongruencias... Los desafíos de lo puberal, en el sentido de Gutton (1991), requieren pensar sexuación, genitalidad y alteridad (en el sentido de la diferencia de las generaciones y de las diferencias o similitudes entre sujetos). ¿Cómo podemos pensar estos conceptos?

Ya hace tiempo propongo trabajar adueñándose de los objetos de la cultura y analizando en la transferencia los usos que les dan los pacientes en las sesiones. Lo propuse a través de mangas, videojuegos, y también recurriendo a películas de género, sobre todo subrayando el modo en que la muerte permitía pensar el tema del sexo, si no el del género. Si las tres teorías sexuales infantiles freudianas (Freud, 1905) tienen que ver con la manifestación del niño, el modo de diferenciación entre hombres y mujeres, e incluso la naturaleza de los encuentros sexuales, entonces yo planteo que todo objeto de la cultura utilizado en sesión, como los mangas, videojuegos, películas de género, rap, sirve para estructurar teorías sexuales juveniles. Estas teorías permiten formalizar las incertidumbres de la filiación y los modos de liberación de las figuras parentales; también permiten dotar al cuerpo de signos distintivos de elección, tanto como de maldición, y revelar, probablemente, lo que permite distinguir los signos de lo masculino y lo femenino en un momento dado de la cultura.

El héroe con cicatriz que traje a colación una vez más con Olga desde su reivindicación del escudo de los soles negros de la melancolía en la palma de su mano es, en sus cuatro características estructurales, la figura que articula narrativamente las cuestiones del género o del sexo en las teorías sexuales. Entre las cuatro características estructurales que definen al héroe con cicatriz (1. Problema en la filiación; 2. Marca en el cuerpo; 3. Incertidumbre sobre el género o la humanidad; 4. Búsqueda con resolución violenta), la tercera, es decir, el tema de la inhumanidad, se convierte en la variación posible de esta doble cuestión del género y de lo que también llamo "el sexo del sexo”. Mi análisis también entiende la cuarta característica estructural, a saber, la de la búsqueda, como un acercamiento al enigma de lo femenino, del cuerpo femenino, cuyas articulaciones interrogan lo erótico tanto como lo genital. Así, planteo que las teorías sexuales juveniles son transmitidas narrativamente en la figura del héroe de la cicatriz.

El héroe se enfrenta al proceso de la sexuación por su cicatriz. El signo-cicatriz se inscribe en el vector de la dirección del discurso, con el fin de que el analista se convierta en superficie de esta dirección (por proyección) y se encuentre necesariamente atrapado en el juego de deformaciones y perspectivas de esos signos. Los fragmentos de la cultura, cualesquiera sean, pueden verse elevados a la dignidad de estructuras lógicas, permitiendo pensar teorías sexuales juveniles, tanto como una novela adolescente (Bonnet, 2011), o incluso modos de estructuración de lo erótico por medio de signos y cicatrices. La cicatriz que encontramos en Olga no es más que el nombre espectacular de una serie de funciones elaborativas y simbólicas que se combinan en el juego de los signos del cuerpo, o sobre el cuerpo, forjando procesos adolescentes. Los signos, las marcas, interrogan el género y la genitalidad organizándolos en una relación de ensamble a través de los medios que la lengua del relato y de la retórica permite en la sesión.

Por el momento, esta es mi propuesta de formalización de las tres teorías sexuales juveniles:

- primero, en lugar de la teoría del pene: los escudos y la cicatriz son andróginos y se leen, se oponen, se apoyan, surgen o se sueltan del cuerpo del otro redefiniendo la naturaleza del género y su función. Se trata de una teoría de los escudos genitales;

- segundo, en lugar de las teorías del parto: los cuerpos con género se penetran o son penetrados en teatros de violencias incesantes. Sus prototipos son devoración, decapitación y desmembramiento, fusión de elementos opuestos que perturban los ordenamientos orificiales heredados de lo infantil. Se trata de una teoría de los (dos) cuerpos empalmados o, más exactamente, del abrazo del héroe con cicatriz; 
- tercero, en lugar del prototipo de la lucha de dos en el abrazo erotizado: los escenarios puberales genitalizados enfrentan a uno(a) con el grupo o la horda violenta, incluso violadora. Se trata entonces de una teoría de la prueba del héroe frente a la horda.

Estas teorías sexuales juveniles, cuando se las pone en tensión con las teorías sexuales infantiles freudianas, contribuyen a devolver al tema de la bisexualidad no un valor prehistórico, sino un valor casi performativo que revela modos deseantes y escenarios deseantes. Esos escenarios se despliegan bajo transferencia en el marco de las sesiones a partir de la articulación de escudos del cuerpo erotizados con escenas puberales que se encierran en relatos, o en lo que podría denominar "novelas de la sexuación". Una de mis preocupaciones actuales consiste en pensar cómo las teorías sexuales infantiles están en el núcleo de las teorías sexuales juveniles y en qué medida el análisis revela su inclusión en la transferencia.

A través de la escena que ordena en la transferencia, Olga instala ante mi mirada una parte de su cuerpo que se está revelando. Gira la palma de su mano que tiene una cicatriz construyendo un marco de limitación y señalamiento de su ojo entre los dedos. Deja pasar la luz y me mira a la vez que se expone a mi mirada. ¿A qué teoría sexual juvenil puede referirse esta escena articulada con la mirada del monstruo en Freaks? ¿Cómo logran conjugarse la mirada a cámara y la mirada a través de la cámara con una escena puberal y un escudo?

No los invito a pensar en una sola, sino en dos teorías sexuales juveniles. En efecto, según la primera teoría sexual juvenil, el lugar de la cicatriz y del escudo parece presente y duplicado por la referencia al monstruo que mira. Olga expone y, más precisamente, me expone su escudo y el marco, de modo cinematográfico, por medio del juego de la luz y del abanico de los dedos. Pero eso se articula también con la segunda teoría sexual juvenil, ya que la mirada se ordena frente a una doble mirada, la del monstruo contado y la "mía", convocada en sesión. El empalme de los cuerpos en el campo de lo escópico adquiere transferencialmente un valor puberal por cuanto sexualiza, o tal vez erotiza, en la transferencia, el momento de interlocución y de nombramiento.

Para sostener este análisis, propongo proceder con una serie de formulaciones lógicas que instalan a la vez la lógica de escenas puberales y, de modo más clásico, la lógica del fantasma:
- el monstruo la mira (mirada a cámara);

- ella es mirada por el monstruo;

- ella me mira;

- ella me muestra su cicatriz (escudo);

- yo veo la cicatriz;

- yo la veo mirarme (escena puberal);

- ella se nombra "monstruo";

- ella es el monstruo que me mira;

- Olga ME dice que ella ES un MONSTRUO.

La sesión analítica es el espacio de una inversión de las figuras en el centro mismo de la transferencia. Olga se ofrece a la vista del analista como ella misma vio al monstruo que la miraba desde la película. La mirada a cámara dentro de la escena se transforma o invierte dentro de la sesión, en la transferencia, bajo la forma de la mirada a través de la cámara. Además, la adolescente se deja ver ante la mirada del clínico. Así, la herida en la mano, finalmente, es el soporte secundario en relación con su exposición a y bajo la mirada. El hecho de mirarla se convierte en lo que está en juego en la sesión.

Las teorías sexuales juveniles permiten detectar cómo las cuestiones del cuerpo en su tensión con las marcas y cicatrices, las cuestiones de la mirada y de la exposición a la mirada se mezclan transferencialmente. En el análisis, Olga pasa de la mirada a cámara a la mirada a través de la cámara, como pasa de la posición de la mirada sobre el cuerpo del otro a la exposición de un escudo de su cuerpo. Los signos y escudos de lo femenino y lo masculino dependen, por consiguiente, no tanto de una serie de normas sociales esperadas, sino más bien de una disposición en el eje de la mirada y de una construcción retórica del género.

Olga se inscribe en, bajo y a través de la mirada que ordena una búsqueda del género cuyas disposiciones en términos de signos de feminidad y masculinidad parecen depender de quién mira y quién se expone a quién. El escudo de la mano-herida cobra sentido en el juego de nuestras miradas inscritas en el eje de la transferencia. Así, mediante el nombre mismo en que se convierte el término de "monstruo", ella hace surgir un juego de posesivos que permite movilizar en la transferencia problemáticas juveniles. Olga se convierte en mi monstruo: "¿Sabe?, no le dije el título de la película; en inglés es Freaks, creo que quiere decir 'los monstruos'... Yo soy su monstruito y solo usted me escucha, pero para eso debo pagar el precio; le pago con mi plata [fric], con mi freaks, Mr. Bonnet, ¿lo oye? Le pago con mi freak". 
Un monstruo cuyo valor inscrito bajo la mirada del analista adquiere una apariencia casi romántica. El posesivo insiste de manera casi más esencial que el nombre mismo: "soy su monstruito". Invito a la reflexión sobre el hecho de que el juego de palabras entre Freaks (monstruo) y fric (plata, dinero) permite a Olga designar, en el cruce del costo y el valor, el intercambio de dinero y de miradas como verdaderos testigos de la transferencia. "Le pago con mi plata [fric]" se convierte en el enunciado decididamente complementario e invertido de "soy

Traducción: Salomé Landívar su monstruito". El analista pertenece a Olga, Olga pertenece al analista, en un juego de miradas cruzadas y dirigidas. Olga paga el precio de la carne con la cicatriz, signo de la herida cuya culpa me atribuye a mí. Olga suspende por un momento su búsqueda de pertenencia a una categoría de género normada, para explorar más bien la dinámica de las miradas cruzadas. Olga paga con su dinero atribuyéndome un lugar específico. Olga, mediante el juego de las miradas y los nombramientos, permite a las teorías sexuales juveniles atravesar el trabajo analítico.

\section{Referencias}

Arasse, D. (1982). Frances Yates et les labyrinthes occultes de l'histoire. Débat, 22, 41-48.

Arasse, D. (1992). Le détail, pour une histoire rapprochée de la peinture. París: Flammarion [trad. esp.: (2008). El detalle, para una historia cercana de la pintura, traducción de Paloma Ovejero. Madrid: Abada].

Arasse, D. (2000). On n'y voit rien. Descriptions. París: Denoël.

Barthes, R. (1966). Introduction à l'analyse structurale des récits. Communications, 8. Barthes, R. (1981). L'analyse structurale du récit. París: Seuil [trad. esp.: Barthes, R. y otros (1972). Análisis estructural del relato. Buenos Aires: Editorial Tiempo Contemporáneo].

Bonnet, C.; Pechikoff, S. (2007). Guenièvre en ses blasons. Adolescence, 60, 341-346.

Bonnet, C.; Pechikoff, S. (2011). Roman adolescent et scènes pubertaires. Adolescence, 78, 787-800.

Bonnet, C.; Petit, L.; Pasquier, A. (2014a). Portrait de l'adolescent en héros à la cicatrice. Psychologie clinique, 38, 45-54.

Bonnet, C.; Pechikoff, S.; Petit, L. (2014b). De l'exposition du héros aux blasons du corps adolescent. Topique, 126, 25-38.

Bonnet, C. (2018). L'œil de la caméra et la rhétorique de l’image. Ética y Cine Journal, 8, 2 [trad. esp.: “El ojo de la cámara y la retórica de la imagen”, traducción de Noelia Luzar, Ética y Cine Journal, 8, 2].

Browning, T. (productor y director). (1932). Freaks [cinta cinematográfica]. Estados Unidos: Metro-Goldwyn-Mayer

Foucault, M. (1996). L’arrière fable. En Dits et écrits. París: Gallimard [trad. esp.: (2005). La trasfábula. En De lenguaje y literatura, traducción de Isidro Herrera. Barcelona: Paidós].

Foucault, M. (1966). Les mots et les choses. París: Gallimard [trad. esp.: (1968). Las palabras y las cosas, traducción de Elsa Cecilia Frost. Buenos Aires: Siglo XXI].

Freud, S. (1905, 1962), Trois essais sur la théorie sexuelle. París: Gallimard [trad. esp.: (2005). Tres ensayos de teoría sexual. En Obras Completas, traducción de José Luis Echeverry. Buenos Aires: Amorrortu, t. VII].

Gutton, P. (1991). Le pubertaire. París: PUF [trad. esp.: (1993). Lo puberal. Buenos Aires: Paidós].

Gutton, P. (1996). Adolescens. París: PUF.

Lévi -Strauss, C. (1958). Anthropologie structurale. París: Gallimard [trad. esp.: (1959). Antropología estructural. Buenos Aires: Siglo $\mathrm{XXI}]$.

Vernet, M. (1983). Le regard à la caméra. Iris, 2.

Yates, F. (1975). L'art de la mémoire. París: Gallimard [trad. esp.: (2005). El arte de la memoria, traducción de Ignacio Gómez de Liaño. Madrid: Siruela].

1 La palabra fric (plata) en francés se pronuncia de modo similar a freak (monstruo) en inglés [N. de la T.]. 